๑ Entomologica Fennica. 14 November 2003

\title{
The phenology of Triphleba Rondani species (Diptera: Phoridae) in moist pine forests in the Białowieża Forest
}

\author{
Ewa Durska
}

\begin{abstract}
Durska, E. 2003: The phenology of Triphleba Rondani species (Diptera: Phoridae) in moist pine forests in the Białowieża Forest. — Entomol. Fennica 14: $177-182$.
\end{abstract}

The phorid material was collected in 1986 and 1987, using yellow plastic bowls attached to crowns of pines (Pinus silvestris) or placed on the ground in pine plantations, from April to October. Triphleba trinervis occurred only in autumn, while T. opaca, T. nudipalpis and T. minuta occurred both in spring and autumn. Among the latter group of species, T. opaca had its abundance peak in spring, but $T$. minuta peaked in autumn. $T$. luteifemorata and $T$. lugubris were caught from the late summer to the end of October. Only a few specimens of $T$. crassinervis were observed from May to June. The phenology of eudominant species Triphleba opaca and T. trinervis was characterized by one abundance peak. The majority of the Triphleba species in this study are known to occur during the low-temperature period (November-March). $T$. trinervis, a late-autumn dominant, clearly preferred temperatures lower than those preferred by $T$. opaca, a spring dominant.

Ewa Durska, Museum and Institute of Zoology, PAS, Wilcza 64, 00-679 Warszawa,Poland; E-mail: edurska@miiz.waw.pl

Received 2 July 2002, accepted 14 January 2003

\section{Introduction}

The genus Triphleba includes about 90 species known from all over the world, with an exception of the Afrotropical Region (Disney 1994). At present, about 55 species have been described from Europe. Of the 33 species found in Poland, 14 have been recorded in the Białowieża Forest (Disney 1991, Durska 1996, Durska 2001a, Durska 2001b).

The scuttle flies overwinter as eggs, larvae, pupae, and also as hibernating imagines. Some species of the genus Triphleba are known to be cold adapted species, whose adults are active in winter. Among them are the species with reduced wings or wings with a ragged outer margin (Disney 1994, Mostowski \& Disney 2001, Soszyńska \& Durska 2002). Soszyńska \& Durska (2002) noted that abdomens of few females of $T$. trinervis, sampled in January, were full of matured eggs. Little is known about most species and seasonal fluctuations of the genus Triphleba because of their unusual phenology.

The present paper supplements the earlier papers on secondary succession of scuttle-fly communities and on the phenology of adult scuttle flies in four age-classes in moist pine (Pinus silvestris - Scots pines) forests in the Białowieża Forest (Durska 2001a, Durska 2002). In Poland, secondary succession of moist pine forest lasts 


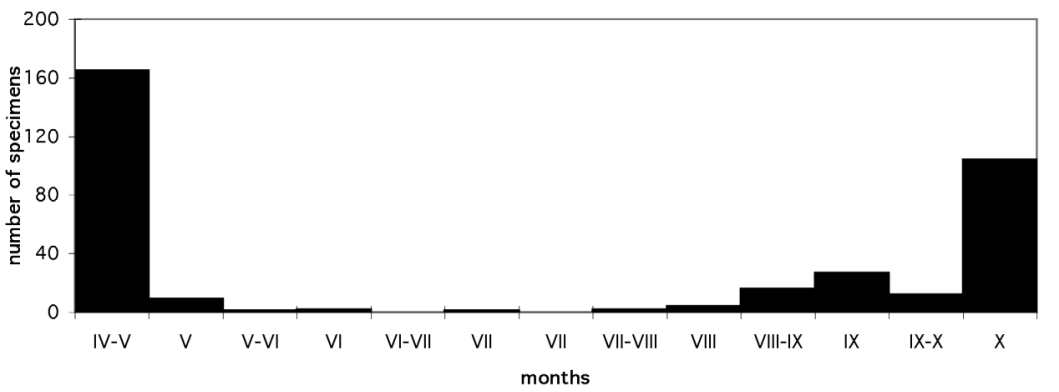

Fig. 1. The phenology of Triphleba spp. in moist pine stands in the Białowieża Forest, in 1986-1987 (age classes combined).
$120-150$ years (pine plantation or culture, younggrowth, small- and large-pole timber, mature or old-growth tree stand) (Szujecki 1980).

\section{Study area}

Studies concerning secondary succession of scuttle flies in the Białowieża Forest were carried out in the forest of Starzyna Division (District Hajnówka). Three areas were selected in the following divisions: 538 (Ba, Bc, Bd, Bf), 634 (Bc, $\mathrm{Ef}), 667 \mathrm{Bf}$ and $668\left(\mathrm{Ad}_{2}, \mathrm{Af}_{1}, \mathrm{Cc}\right)$. At each of these areas, several-hectare, even-aged forest plots were chosen: pine plantation or forest culture (the age of the saplings 4-8 years), young-growth or thicket (the age of the trees 16-22 years), large pole timber or premature stands (age-class III; the age of the trees 50 years) and old-growth or mature stands (the age of the dominant trees 140145 years). The soil and phytosociology of the selected stands were homogeneous to the human eye. The study areas represent the sub-boreal variety of the Peucedano-Pinetum association (Matuszkiewicz et al. 1993).

\section{Material and methods}

The phorid material was collected in 1986 and 1987, using yellow plastic bowls (diameter ca. $18 \mathrm{~cm}$ ) with $75 \%$ ethylene glycol and detergent. The traps were attached to crowns of pines (in thickets - at height 2-3 m, in premature stands — ca. $10 \mathrm{~m}$, and in the old-growth stands $15-20 \mathrm{~m}$ above the ground) or, in pine plantations, placed on the ground. The trapping lasted from April to October. The traps were usually emptied fortnightly.
Five traps ( 1 per tree) were installed on each plot. Altogether 60 traps were run in the four standage classes. The material contained 57181 phorid imagines, but 14 Triphleba species made up about $0.6 \%$ (343 specimens).

To describe the dominance structure of communities, a dominance index $(D)$ was used (Durska 2001a):

$$
D=n / N \times 100 \%
$$

where $n=$ the abundance of a given species, and $N=$ the accumulated abundance of all Triphleba species.

The dominance index $(D)$ was used to classify the species into four classes: (1) eudominant (over 15.0\%), (2) dominant $(5.1 \%-15.0 \%)$, (3) subdominant $(1.1 \%-5.0 \%)$ and (4) accessory species (below 1.0\%).

\section{Results}

The eudominant Triphleba species reached their abundance peaks during a different period than the other species of this investigation. Most Phoridae have a lower maximum in spring (May) and a higher one in autumn (September). The spring peak of Triphleba species (at the turn of April and May) was higher (by 61 specimens) than the autumn peak (end of October). A rapid increase in abundance of Triphleba specimens collected during the course of the year, followed by a decrease, which is characteristic for scuttle-flies, was observed at the turn of August and September and in September, but it was not remarkably high (Fig. 1).

The saprophagous-necrophagous species: Triphleba opaca (Meigen) (abundance over 50\%), 


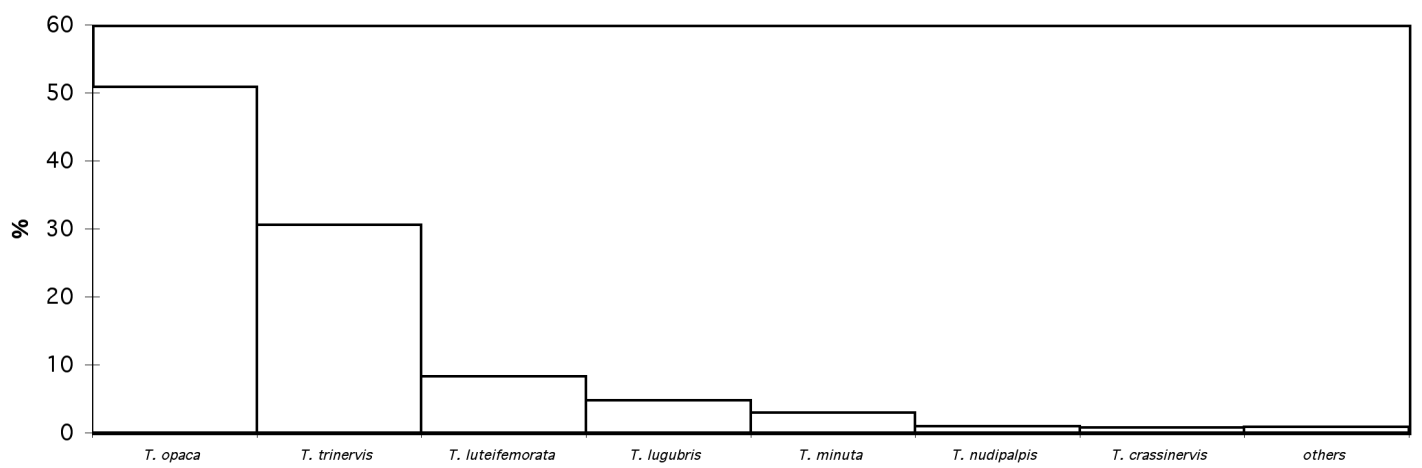

Fig. 2. The dominance structure of Triphleba spp. in moist pine stands in the Białowieża Forest., in 1986-1987 (age classes combined).

Fig. 3. The phenology of Triphleba opaca, T. trinervis and $T$. luteifemorata in moist pine stands in the Białowieża Forest, in 1986-1987 (age classes combined).

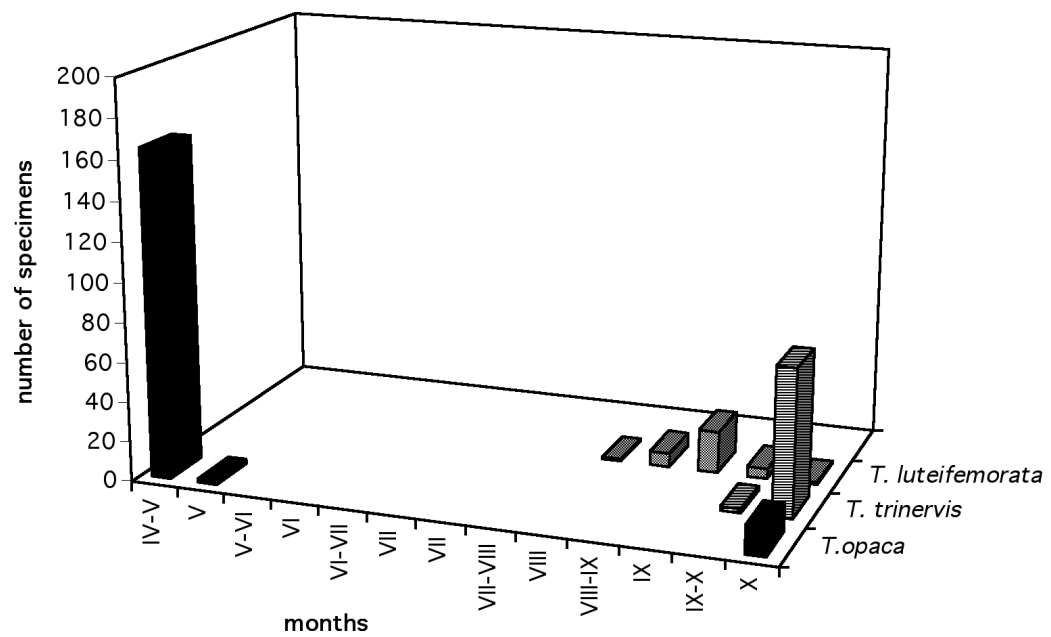

T. trinervis (Becker) (abundance over 30\%) and T. luteifemorata (Wood) (abundance over 8\%) were the eudominant and dominant species among the species of the genus Triphleba (Fig. 2).

Triphleba trinervis occurred only in autumn, while T. opaca, T. nudipalpis and T. minuta were caught both in spring and autumn. Among the latter group of species, T. opaca was more abundant in spring, but T. minuta in autumn. T. luteifemorata and $T$. lugubris was noticed from the late summer to the end of October. Only few specimens of $T$. crassinervis were observed from May to June (Figs. 3 and 4).

T. opaca peaked in abundance in pine plantations and in old-age stands. At the turn of April and May some specimens in copula were detected in both habitats. The phenology of T. opaca has previously been documented by Schmitz (1943), the spe- cies having one generation (univoltine) and being characterized by a single abundance peak (AprilMay). In the present study, the first $T$. trinervis individuals were recorded on 25 September. The abundance of this necrophagous species was at its highest in the young-growth stands, compared to other stands. T. trinervis, the late-autumn dominant species, clearly preferred temperatures lower than $T$. opaca, which dominated the catches in spring. The first individuals of T. luteifemorata were collected in August in the young-growth stands. This species reached almost equally high abundance in the largepole timber stands and in the mature stands (Figs. 5-8). T. trinervis and T. luteifemorata may have several generations a year (multivoltine life cycle) (Buck 1997, Durska 1996, Durska 2001a).

The first individuals of T. lugubris (Meigen) the subdominant species were collected in July. 


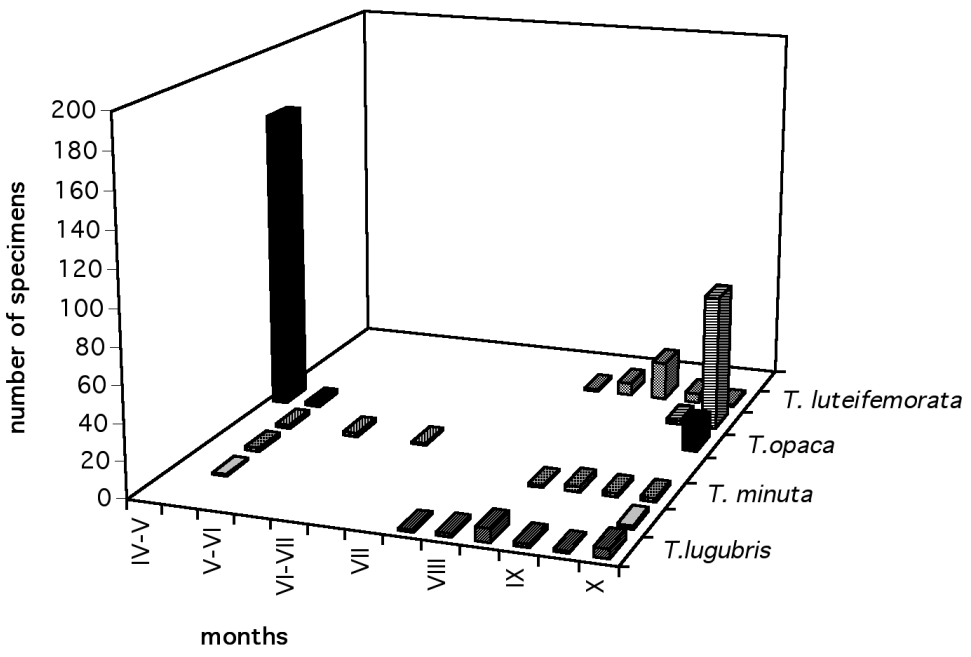

Fig. 4. The phenology of Triphleba lugubris, T. nudipalpis, $T$. minuta and $T$. crassinervis in moist pine stands in the Białowieża Forest, in 1986-1987 (age classes combined).

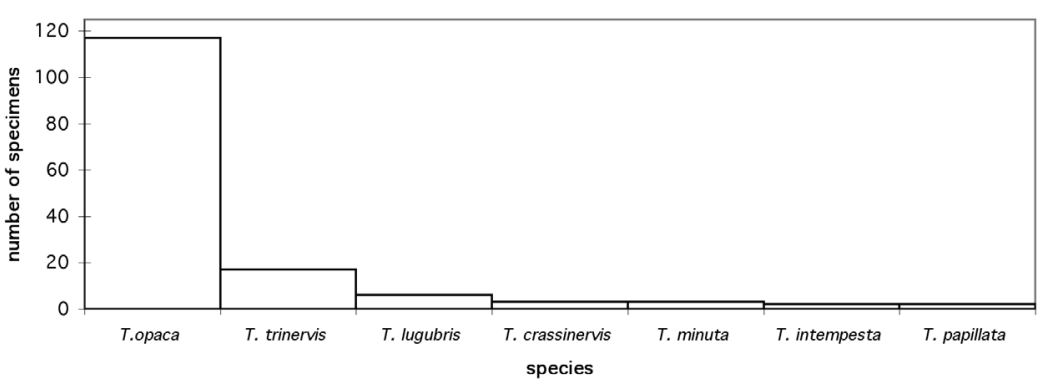

young-growth

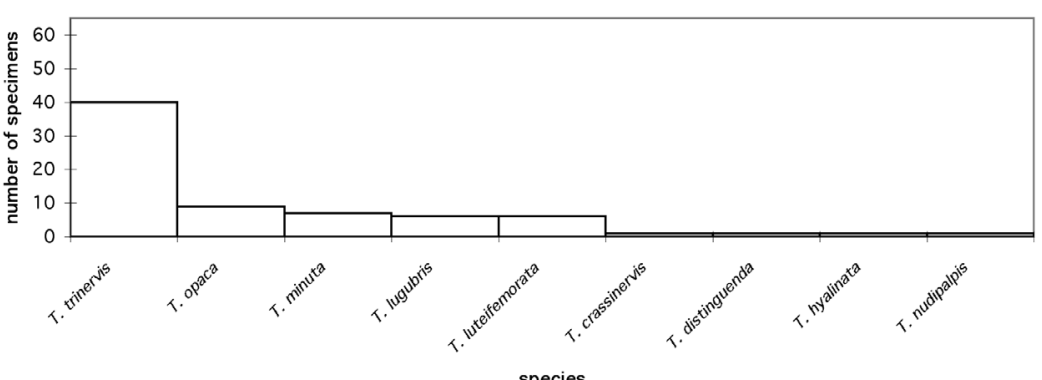

Fig. 5. The dominance stucture of Triphleba spp. in pine plantations in the Białowieża Forest, in 1986-1987.

Fig. 6. The dominance structure of Triphleba spp. in young-growth pine stands in the Białowieża Forest, in 1986-1987.
The highest abundance of this saprophagous and facultative parasite species was recorded in pine plantation and young-growth stands. The individuals of $T$. minuta (Fabricius), the subdominant species associated with fungi, were collected in pine plantations and in the young-growth (the highest abundance). The necrophagous $T$. nudipalpis (Becker) appeared in May and again in October in the young-growth stands and in the old-growth stands. The first individuals of $T$. crassinervis
(Strobl) were collected in pine plantations in May and June. This species was also recorded in July, in the young-growth stands and in June, in the large-pole timber stands (Figs. 5-8).

The other species of Triphleba had very low catches, with only a few specimens. Triphleba hyalinata (Meigen) occurred in August (in younggrowth) and in October (in old-growth), $T$. intempesta (Schmitz) abundance peaked in September (in pine plantations), that of T. papillata 
Fig. 7. The dominance structure of Triphleba spp. in moist, large-pole timber pine stands in the Białowieża Forest, in 1986-1987.

Fig. 8. The dominance structure of Triphleba spp. in the moist old-growth pine stands in the Białowieża Forest, in 1986-1987.

(Wingate) peaked in May (in pine plantations) and that of T. collini Schmitz at the end of August (in large pole timber). Moreover, T. distinguenda (Strobl) abundance peaked at the end of October (in young-growth), that of T. smithi Disney in August (in old-growth) and that of T. subcompleta Schmitz in October (in old-growth).

\section{Discussion}

In the phorid communities of moist pine forest, species of the genus Triphleba were the ones with the earliest spring abundance peak. T. opaca was the spring eudominant species. However, the lateautumn peak (in October) was affected by an abrupt change in the abundance of $T$. trinervis. The abundance increase at the turn of August and September overlapped with a considerable increase in the abundance of $T$. luteifemorata. The author observed individuals of this species during the spring (April-May) in the old-growth stands of Bory Tucholskie Forest and Puszcza Biała Forest. In the old-growth stands of both of these areas, $T$. trinervis was also observed in the latter half of July and in September, but $T$. crassinervis occurred in August in the old-growth stands in Bory Tucholskie Forest (Durska 1996).
Species of the genus Triphleba are well known for their adaptation to low temperatures. Their activity has been recorded in late autumn, in winter and in early spring: on snow (nival species) and under snow (subnival species). Soszyńska \& Durska (2002) recorded six Triphleba species, namely T. excisa, $T$. intempesta, T. opaca, T. palposa, T. papillata and $T$. trinervis, active on snow in different parts of Poland. The reduced or ragged wings and other striking features, such as adaptation to sub-zero winter temperatures, were observed in T. trinervis from Poland and T. recidopennis from Kazakhstan (Mostovski \& Disney 2001, Soszyńska \& Durska 2002).

A similar phenology to $T$. trinervis (multivoltinism) and a clear preference for low temperatures was recorded in T. autumnalis (Buck 1997, Disney 1983, R. H. L. Disney pers. comm.). Triphleba species can occur year-round, like $T$. nudipalpis, or throughout the summer (from May to October), like T. dudai (Buck 1997). However, the majority of the Triphleba species are known to occur during low-temperature period (NovemberMarch). Insect activity during the cold part of the year has some positive aspects, especially for necrophagous species. They are able to avoid competition, predation and parasitization during the larval stage. Moreover, the snow surface is probably a useful shelter during reproduction period. 
Acknowledgements. I thank especially Dr. R. Henry Disney for his kind help. I am grateful to Dr. Matthias Buck for his comments on an earlier version of the manuscript. This work was funded by the Komitet Badań Naukowych PAN (Committee for Scientific Research, PAS).

\section{References}

Buck, M. 1997: Untersuchungen zurökologischen Einnischung saprophager Dipteren unter besonderer Berücksichtigung der Phoridae und Sphaeroceridae (Brachycera/ Cyclorrhapha). - PhD thesis, Universität Ulm, Germany.

Disney, R. H. L. 1983: Scuttle flies Diptera, Phoridae (except Megaselia). — In: Handbook for the Identification of British Insects 10: 1-81.

Disney, R. H. L. 1991: Family Phoridae. - In: Soós, A., Papp, L. (eds.), Catalogue of Palaearctic Diptera. Volume 7 (Dolichopodidae-Platypezidae): 143-204. Akademiai Kiado, Budapest, Hungary.

Disney, R. H. L. 1994: Scuttle flies: The Phoridae. Chapman \& Hall, London. 467 pp.

Durska, E. 1996: The species composition and structure of scuttle fly communities (Diptera: Phoridae) in mature tree stands in pine forests at different stages of habitat degradation. - Fragm. Faun. 39: 267-285.
Durska, E. 2001a: Secondary succession of scuttle fly (Diptera: Phoridae) communities in moist pine forest in Białowieża Forest. — Fragm. Faun. 44: 81130.

Durska, E.2001b: Zadrowate (Diptera: Phoridae). — In: Gutowski, J. M. \& Jaroszewicz, B. (eds.), Catalogue of the fauna of Białowieża Primeval Forest: 286-289. IBL, Warszawa, Poland.

Durska, E. 2002: The phenology of dominant scuttle-fly (Diptera: Phoridae) species in the Białowieża Forest. — Entomol. Fennica 13: 123-127.

Matuszkiewicz, J., Degórski, M. \& Kozłowska, A. 1993: Description of the plant association structure and soils of pine forest stands situated in five regions of Poland. - In: Species composition and structure of pine forests fauna in Poland. Part I. Fragm. Faun. 36: 13-36.

Mostovski, M. B. \& Disney R. H. L. 2001: A remarkable new species of Triphleba Rondani (Diptera:Phoridae). — Studia Dipterologica 8: 557-562.

Schmitz, H. 1943. Phoridae. — In : Lindner E. (ed.), Die Fliegen der palaearctischen Region 4(33) (Lieferung 149): 161-192.

Soszyńska, A. \& Durska, E. 2002: Cold-adapted scuttleflies species of Triphleba Rondani (Diptera, Phoridae). - Annales Zoologici (Warszawa) 52(2): 155-159.

Szujecki, A. 1980: Ekologia owadów leśnych. — PWN, Warszawa, Poland. 603 pp. 